\title{
Supercooling capacity and cold hardiness of the eggs of the grasshopper Chorthippus fallax (Orthoptera: Acrididae)
}

\author{
Shu-GuANG HAO and Le KANG* \\ State Key Laboratory of Integrated Management of Pest Insects and Rodents, Institute of Zoology, The Chinese Academy of \\ Sciences, 25 Beisihuanxi Road, Haidian District, Beijing 100080, China
}

Key words. Cold hardiness, supercooling point, acclimation, overwintering ability, Chorthippus fallax

\begin{abstract}
Cold tolerance of the eggs of the grasshopper, Chorthippus fallax (Zubovsky), was examined in the laboratory. Egg supercooling points varied from $-6^{\circ} \mathrm{C}$ to $-32.4^{\circ} \mathrm{C}$ and could be divided into two groups. The supercooling points of the higher SCP group ranged from $-6^{\circ} \mathrm{C}$ to $-14^{\circ} \mathrm{C}$ and those of lower SCP group from $-21.8^{\circ} \mathrm{C}$ to $-32.4^{\circ} \mathrm{C}$. Although low temperature acclimation could slightly decrease the supercooling points of eggs, the effect was not significant for all embryonic developmental stages or acclimation periods. The supercooling capacity was obviously different between pre-diapause, diapause and post-diapause embryonic stages. The mean supercooling points of pre-diapause and diapause eggs were similar; $-28.8 \pm 1.6^{\circ} \mathrm{C}$ and $-30.7 \pm 1.0^{\circ} \mathrm{C}$ for non-acclimated eggs and $-29.5 \pm 1.3^{\circ} \mathrm{C}$ and $-31.18 \pm 0.8^{\circ} \mathrm{C}$ for acclimated eggs respectively. However, the mean supercooling points of postdiapause eggs were significantly higher; $-12.9 \pm 5.6^{\circ} \mathrm{C}$ for non-acclimated and $-13.5 \pm 4.5^{\circ} \mathrm{C}$ for acclimated eggs respectively. The survival rates of diapause eggs at $>-25^{\circ} \mathrm{C}$ were not significantly different from that at $25^{\circ} \mathrm{C}$, but survival rates at $<-30^{\circ} \mathrm{C}$ decreased significantly. The lethal temperature $\left(\mathrm{Ltemp}_{50}\right)$ for a $12 \mathrm{hrs}$ exposure was $-30.1^{\circ} \mathrm{C}$, and the lethal time $\left(\mathrm{Ltime}_{50}\right)$ at $-25^{\circ} \mathrm{C}$ was 44 days. Since the SCPs of diapause eggs was similar to their Ltemp s0 $_{0}$, we may consider the supercooling capacity of such eggs is a good indicator of their cold hardiness and the species is a true freeze avoiding insect. Based on the analysis of local winter temperature data, pre-diapause and diapause, low SCP eggs can safely survive severe winters, but not the post-diapause, high SCP eggs. The importance of the overwintering strategy and the relationship between diapause and cold hardiness of this species is discussed.
\end{abstract}

\section{INTRODUCTION}

Many strategies have been developed by insects to survive adverse environmental conditions. The egg stage is the principal overwintering stage in many insects and other terrestrial arthropods, and considerable interest has been shown by entomologists in the cold resistance of eggs (Sømme, 1982, 2000; Gehrken, 1989; Hanson \& Craig, 1994; Block et al., 1995; Strathdee et al., 1995; Shintani \& Ishikawa, 1999; Jing \& Kang, 2003). Cold hardiness is defined as the capacity of a species to survive long or short term exposure to low temperature (Lee, 1991). This capacity is influenced by many factors, including developmental stage, genetic potential, season, duration of exposure and nutritional status. Insects are commonly classified into two main categories: freeze intolerant and freeze tolerant (Storey \& Storey, 1988; Lee, 1991). The supercooling point (SCP) is considered an indicator of the lower lethal temperature, but many researchers argue that the SCP is not a reliable index of cold hardiness since some insects die before their body freezes (Bale, 1993, 1996). Neither the lower lethal temperature of freeze tolerant insects, nor the supercooling capacity of freeze intolerant insects should be considered the only measure of the cold hardiness of a given species (Nedvěd, 2000a). In addition, the ability to survive prolonged periods of cold exposure must be evaluated at temperatures both above and below the freezing point of the insects' body fluids (Sømme, 1996).
Cold hardiness has been studied in many insects and mites (Lee, 1991; Nedvěd, 2000b; Sømme, 2000; Bale, 2002). However, apart from several papers documenting the SCPs of Locusta migratoria (Lozina-Lozinskii, 1974; Jing \& Kang, 2003), Myrmeleotettix palpalis, Aeropedellus varigatus minutus and Dasyhippus barbipes (Block et al., 1995), and Hemideina maori (Ramløv et al. 1992; Ramløv, 1999), there are few available data on cold hardiness of Orthoptera, especially the Acrididae.

The grasshopper, Chorthippus fallax (Zubovsky), causes visible grass loss in China's Inner Mongolian steppe region (Li \& Kang, 1991; Lockwood et al., 1994). The species is univoltine and overwinters as eggs in the soil. The eggs are laid in mid/late September and hatch the following July, therefore, $C$. fallax can be considered a late hatching species (Kang \& Chen, 1994a, b). We have observed that the embryos of grasshopper eggs collected from local fields in the mid-November were in stage 9-13 (according to the standard of Van Horn, 1966), and maintenance at a constant $25^{\circ} \mathrm{C}$ indicated that the grasshopper eggs entered diapause in embryonic stage 18-19 (unpublished data). Consequently the grasshopper overwinters as eggs in the pre-diapause embryonic stage. These overwintering eggs will experience a prolonged period of low temperature in winter. Since the cold hardiness of $C$. fallax eggs is critical to determine their survival, it has a major influence on population dynamics in following seasons. Although there have been some ecological studies on C. fallax, including food selection,

\footnotetext{
* Corresponding author. Phone: (86-10) 6255 4979; fax: (86-10) 6256 5689; e-mail: 1kang@panda.ioz.ac.cn
} 
TABLE 1. Mean, standard deviation and range of SCPs of non-acclimated and acclimated pre-diapause eggs of the grasshopper $C$. fallax.

\begin{tabular}{cccccccccc}
\hline Acclimation time(day) & $\mathrm{N}$ & \multicolumn{3}{c}{ Low SCP group } & & \multicolumn{3}{c}{ High SCP group } \\
& & Mean $\left({ }^{\circ} \mathrm{C}\right) *$ & $\mathrm{SD}$ & Range $\left({ }^{\circ} \mathrm{C}\right)$ & & Mean $\left({ }^{\circ} \mathrm{C}\right)^{*}$ & SD & Range $\left({ }^{\circ} \mathrm{C}\right)$ \\
\hline 0 & 22 & -28.8 & 1.608 & $-30.5--24.1$ & & & & \\
30 & 18 & -28.1 & 2.020 & $-31.3--24.5$ & & -7.7 & 1.162 & $-9.0--6.7$ \\
60 & 45 & -29.5 & 1.261 & $-32.4--21.8$ & & -10.5 & 2.803 & $-14.0--6.8$ \\
90 & 31 & -28.9 & 3.186 & $-31.8--21.8$ & & -7.5 & 1.885 & $-10.0--6.0$ \\
\hline
\end{tabular}

*Mean SCP of non-acclimated pre-diapause eggs in the low SCP group was not significantly different from that of acclimated eggs $\left(\mathrm{F}=1.719, \mathrm{df}_{1}=3, \mathrm{df}_{2}=101, \mathrm{P}=0.167\right)$

resource utilization, egg pod location and identification, and population dynamics ( $\mathrm{Li}$ et al., 1983; Li \& Chen, 1985, 1987; Liu et al., 1990; Kang \& Chen, 1994a, b), there has been no comprehensive study of the cryobiology of this species.

Considering this grasshopper as a late hatching species that overwinters as pre-diapause eggs raises two questions: (1) is there a difference in cold hardiness between pre-diapause and diapause eggs? (2) can pre-diapause eggs safely overwinter and hatch in the following July? This study attempts to answer these two questions by investigating the cold hardiness and supercooling capacity of $C$. fallax eggs in different embryonic stages. This research should improve understanding of the overwintering capabilities, survival capacity and population dynamics of this grasshopper in following seasons.

\section{MATERIALS AND METHODS}

\section{Egg origin and collection}

Grasshopper eggs were obtained from adults collected at the Chinese Academy of Sciences Inner Mongolia Grassland Ecosystem Research Station $\left(43^{\circ} 26^{\prime}-44^{\circ} 08^{\prime} \mathrm{N}, 116^{\circ} 04^{\prime}-117^{\circ} 05^{\prime} \mathrm{E}\right.$, and $1000-1050 \mathrm{~m}$ in elevation). Adult grasshoppers were maintained at $28^{\circ} \mathrm{C} \pm 1{ }^{\circ} \mathrm{C}$ during the day and $20^{\circ} \mathrm{C} \pm 1{ }^{\circ} \mathrm{C}$ at night with a photoperiod of $14 \mathrm{~L}: 10 \mathrm{D}$. The grasshoppers were fed on wild host plants collected from the field (Li \& Chen, 1985). Soil from the collection area was sieved through a $2 \mathrm{~mm}$ mesh and placed on the bottom of cages as an oviposition substrate. The soil layer was approximately $15 \mathrm{~cm}$ deep, and was moistened each day. Egg pods were collected from the oviposition cages weekly and prepared for study as follows: egg pods were rinsed from soil into a sieve and placed in small plastic boxes which contained washed silica sand ( 40 mesh) that had been moistened to the point of being wet but without free standing water. The boxes with egg pods and sand were placed in a $25^{\circ} \mathrm{C} \pm 1{ }^{\circ} \mathrm{C}$ incubator for 20 days to obtain pre-diapause eggs (embryos were in about stage 11-13), for 60 days to allow the eggs to reach the diapause stage (embryos were in stage 18-19), and some diapause eggs were placed at $0^{\circ} \mathrm{C} \pm 1{ }^{\circ} \mathrm{C}$ for 90 days to terminate diapause and then transferred to $25^{\circ} \mathrm{C} \pm 1{ }^{\circ} \mathrm{C}$ for 10 days to obtain post-diapause eggs (embryos were in stage 22-23).

\section{Acclimation}

The grasshopper eggs at pre-diapause, diapause and postdiapause embryonic stages were kept at $5^{\circ} \mathrm{C} \pm 1^{\circ} \mathrm{C}$ for $0,30,60$ and 90 days. The SCPs of the eggs were measured on batches of 15-25 eggs from each treatment group (2 eggs were taken from each egg pod).

\section{Determination of supercooling point (SCP)}

The SCPs of eggs at different developmental stages (prediapause, diapause and post-diapause) and from different low temperature acclimation treatments were measured. After the surface of each egg was dried with filter paper, individual eggs were fixed with plastic tape to the tip of a thermocouple which was linked to a recorder (uR100, Model 4152, Yologama Elect. Co., Seoul, Korea). The thermocouple with the egg was placed inside an insulating styrofoam box in a freezer to ensure that the cooling rate was about $1{ }^{\circ} \mathrm{C} \mathrm{min}^{-1}$. The lowest temperature reached before an exothermic event occurred due to release of latent heat was regarded as the supercooling point of the eggs (Zhao \& Kang, 2000; Chen \& Kang, 2002).

\section{Determination of lethal temperature and lethal time}

To evaluate survival at low temperature, for each of 12 treatments, 6 replicates of 20 diapause eggs were exposed to $-25^{\circ} \mathrm{C}$ $\pm 0.5^{\circ} \mathrm{C}$ for $0.5,1,2,4,8,16$ days and to $-15^{\circ} \mathrm{C},-20^{\circ} \mathrm{C},-25^{\circ} \mathrm{C}$, $-30^{\circ} \mathrm{C},-35^{\circ} \mathrm{C}$ and $-40^{\circ} \mathrm{C} \pm 0.5^{\circ} \mathrm{C}$ for $12 \mathrm{~h}$. Additional batches of eggs were kept at $0^{\circ} \mathrm{C} \pm 1{ }^{\circ} \mathrm{C}$ for 90 days, which terminated diapause. After treatment, eggs were removed and kept in dark chambers at $25^{\circ} \mathrm{C} \pm 1^{\circ} \mathrm{C}$. Egg mortality and hatching success were recorded daily for 60 days. Eggs that became flaccid, brown or moldy were considered dead whereas those that were cream-colored and turgid were considered alive (Fisher, 1997).

\section{Statistical methods}

Multi-way Analysis of variance (ANOVA) (SPSS 10.0 Software) was used to determine the effects of constant low temperatures and exposure duration on supercooling points and hatching rate. The Tukey Honest Significant Difference (HSD) test was used to detect significant differences between means. The form of the relationship between survival rate and time or temperature of exposure was determined by Weibull function or Probit analysis (see Kalushkov \& Nedvěd, 2000). The exposure duration that resulted in $50 \%$ survival (Ltime ${ }_{50}$ ), or the exposure temperature that resulted in $50 \%$ survival (Ltemp. ${ }_{50}$ ), was estimated.

\section{RESULTS}

\section{Supercooling capacity and the effects of low temperature acclimation}

The SCPs of 117 non-acclimated and acclimated prediapause eggs at $5^{\circ} \mathrm{C}$ varied from $-6^{\circ} \mathrm{C}$ to $-32.4^{\circ} \mathrm{C}$. The frequency distribution of SCPs was significantly bimodal, indicating the existence of a low (SCP $<-15^{\circ} \mathrm{C}$ ) and a high SCP group $\left(\mathrm{SCP}>-15^{\circ} \mathrm{C}\right)$ (Table 1). Although the mean SCP of non-acclimated pre-diapause eggs in the low SCP group was not significantly different from that of acclimated eggs $\left(\mathrm{F}=1.719, \mathrm{df}_{1}=3, \mathrm{df}_{2}=101, \mathrm{P}=\right.$ $0.167)$, there was a tendency for the number of eggs with 


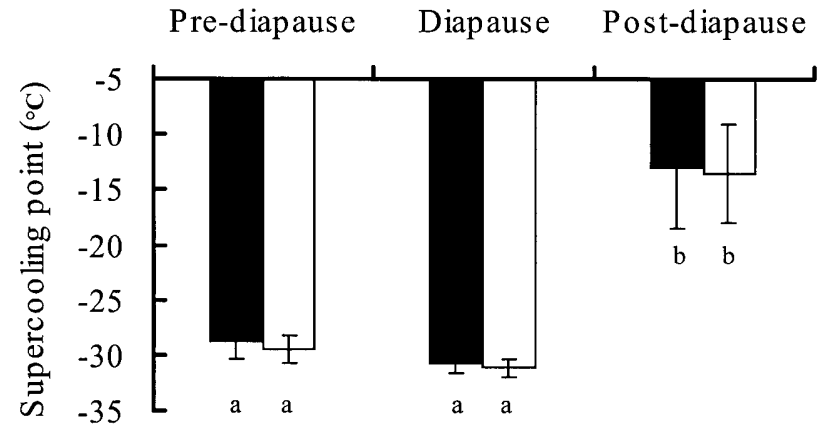

Non acclimated $\square$ Acclimated

Fig. 1. SCPs of C. fallax eggs in different stages of embryonic development, non acclimation and acclimation at $5^{\circ} \mathrm{C}$ for 60 days. Bars (mean $\pm \mathrm{SD}$ ) with the same letter below are not significantly different.

SCPs $<-30^{\circ} \mathrm{C}$ to increase with extended duration of acclimation.

\section{Effects of egg developmental stage on SCP}

Differences in SCP and the effects of low temperature acclimation on the SCP of pre-diapause, diapause and post-diapause eggs were examined. The SCPs of eggs in pre-diapause and diapause conditions were similar, but significantly lower than that of post-diapause eggs $\left(\mathrm{F}_{(2,128)}\right.$ $=55.26, \mathrm{P}<0.0001)$. Though low temperature acclimation could slightly decrease the SCP of eggs from $-28.8 \pm$ $1.6^{\circ} \mathrm{C}$ to $-29.5 \pm 1.3^{\circ} \mathrm{C}$ in pre-diapause eggs, $-30.7 \pm$ $1.0^{\circ} \mathrm{C}$ to $-31.1 \pm 0.8^{\circ}$ in diapause eggs, and from -12.88 $\pm 5.58^{\circ} \mathrm{C}$ to $-13.53 \pm 4.52^{\circ} \mathrm{C}$ in post-diapause eggs, the effect of acclimation was not markedly different $\left(\mathrm{F}_{(1,128)}=\right.$ $0.313, \mathrm{P}=0.577)$, and there was no significant statistical interaction between acclimation and developmental stage $\left(F_{(2,128)}=1.728, P=0.182\right)$. Regardless of whether eggs had been acclimated or not, diapause eggs had the lowest SCPs (Fig. 1).

\section{Low lethal temperature}

The survival rates of diapause eggs exposed to different low constant temperatures for $12 \mathrm{hrs}$ were determined. Survival rates of eggs at $-25^{\circ} \mathrm{C}$ or higher were not signifi-

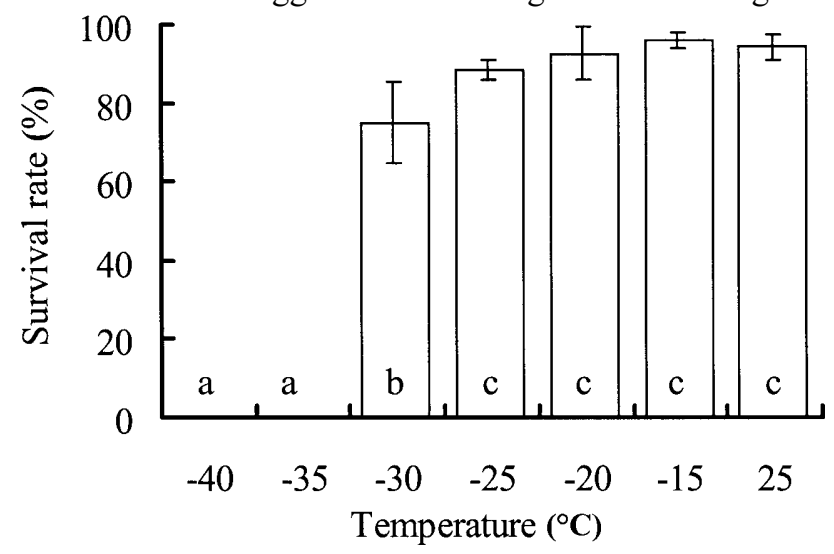

Fig. 2. Survival rate of diapause eggs of $C$. fallax exposed to different low constant temperatures for 12 hours. Bars (mean \pm $\mathrm{SD})$ with the same letter below are not significantly different.

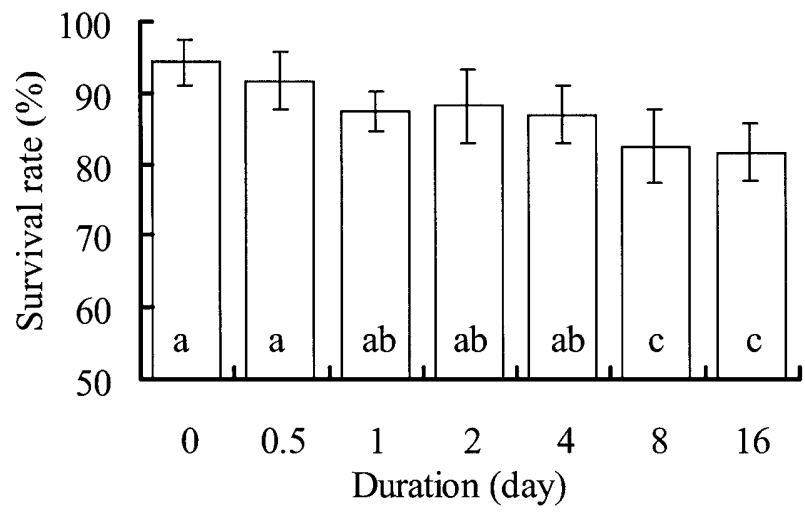

Fig. 3. Survival rate of diapause eggs of $C$. fallax exposed to $-25^{\circ} \mathrm{C}$ for different lengths of time. Bars (mean $\pm \mathrm{SD}$ ) with the same letter below are not significantly different.

cantly different, nonetheless survival rate declined significantly at $-30^{\circ} \mathrm{C}$ and suddenly dropped to zero at $-35^{\circ} \mathrm{C}$ (Fig. 2). The response curve was an asymmetric sigmoid, so that the Weibull function was used to describe the relationship between survival and exposure time. The Weibull function was $\mathrm{P}=1-\exp \left(-(\mathrm{t}+35.008)^{2} / 18.035\right)$ ( $\mathrm{t}$ : temperature, Pearson goodness of fit Chi-square was significant, $\left.\mathrm{df}=34, \mathrm{P}<0.0001, \mathrm{R}^{2}=0.946\right)$. The Ltemp $_{10}$, Ltemp $_{50}$ and Ltemp $p_{90}$ values of diapause eggs exposed to low temperatures for $12 \mathrm{hrs}$ were estimated as $-33.6^{\circ} \mathrm{C},-31.5^{\circ} \mathrm{C}$ and $-28.6^{\circ} \mathrm{C}$ respectively, and the lowest temperature for egg survival was about $-35^{\circ} \mathrm{C}$.

\section{Lethal time}

The survival rates of diapause eggs exposed to $-25^{\circ} \mathrm{C}$ for different periods are shown in Fig. 3. Survival rates of diapause eggs at $-25^{\circ} \mathrm{C}$ decreased slowly with increasing duration of exposure to low temperature. But there was no significant difference between $0 \mathrm{~d}$ and exposures of $0.5,1,2$, and $4 \mathrm{ds}$. Only the survival rates of eggs exposed for 8 and 16 ds were significantly less than those exposed for shorter lengths of time. The dose response curve was not sigmoid, so the Probit function was used to describe their relationship. The function was $\ln (\mathrm{p} /(1-\mathrm{p}))=$ $2.2224+0.05089 \mathrm{t}(\mathrm{t}$ : time, Pearson goodness of fit Chisquare was significant, $\mathrm{df}=40$ and $\mathrm{P}=0.0197, \mathrm{R}^{2}=$ 0.832). Probit analysis of egg survival vs exposure time indicates that the Ltime $_{10}$, Ltime ${ }_{50}$ and Ltime ${ }_{90}$ values of diapause eggs at $-25^{\circ} \mathrm{C}$ were about $87 \mathrm{~d}, 44 \mathrm{~d}$ and $0.5 \mathrm{~d}$ respectively.

\section{DISCUSSION}

\section{Supercooling and survival}

The results of this study show that the SCPs of prediapause eggs could be divided into low and high SCP groups (Table 1). The mean SCPs of eggs were approximately $-29^{\circ} \mathrm{C}$ for the low group (range from $-21.8^{\circ} \mathrm{C}$ to $32.4^{\circ} \mathrm{C}$ ), and $-8^{\circ} \mathrm{C}$ for the high group (range from $-6^{\circ} \mathrm{C}$ to $-14^{\circ} \mathrm{C}$ ). The percentage of eggs in low group was $88 \%$. A substantial number of individual eggs froze at temperature several degrees lower than the mean value, and some eggs had SCPs as low as $-32^{\circ}$. This result was similar to 


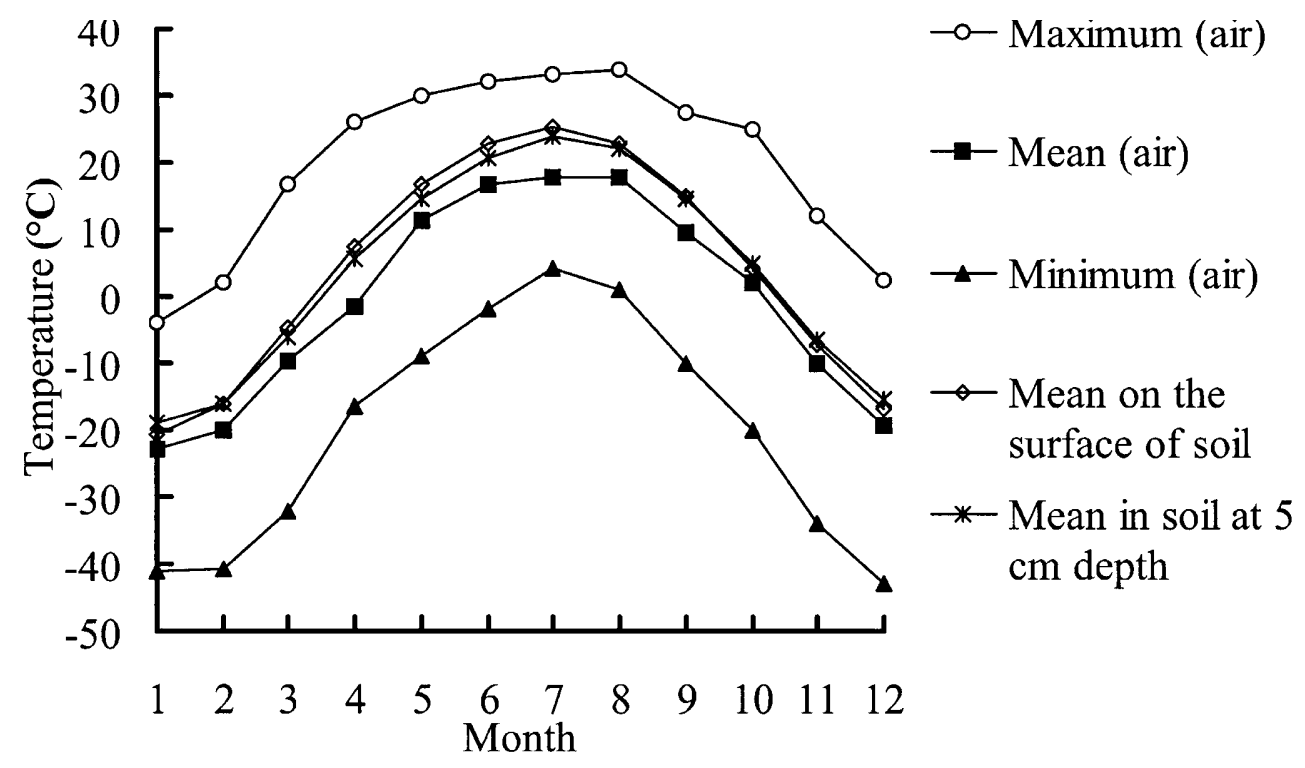

Fig. 4. Maximum, mean and minimum air temperatures at $150 \mathrm{~cm}$ height, soil surface and at $5 \mathrm{~cm}$ below the soil surface recorded at the Inner Mongolia Grassland Ecosystem Research Station during 1970-2000.

those recorded in $M$. palpalis, A. varigatus minutus and $D$. barbipes (early hatching grasshoppers also found in the Inner Mongolian steppe) (Block et al., 1995). It appears that there are two types of overwintering eggs in grasshoppers, some eggs die at relatively high subzero temperatures while others do not.

There was a close correlation between SCP and both lethal temperature and lethal time. The SCPs of diapause eggs were similar to their lethal temperature. The survival rates of diapause eggs of C. fallax at $>-25^{\circ} \mathrm{C}$ and at $25^{\circ} \mathrm{C}$ (control treatment) were not significantly different, while survival rates at $<-30^{\circ} \mathrm{C}$ were significantly decreased (Fig. 2). The Ltemp 50 for $12 \mathrm{hrs}$ was $-31.5^{\circ} \mathrm{C}$, and the mean SCP of diapause eggs was $-30.7^{\circ} \mathrm{C}$ for nonacclimated and $-31.1^{\circ} \mathrm{C}$ for acclimated eggs. Previous studies have demonstrated that the SCP is not a suitable index for cold hardiness of many species as it does not take into account mortality at sub-zero temperatures above the insect's supercooling point (Milonas \& Savopoulou, 1999; Nedvěd, 2000a; Bale, 2002 ). However, a good correlation between survival at low temperature and SCP in several species has also been reported, and in these species it is suggested that the SCP is a reliable indicator of low temperature tolerance (Lee \& Denlinger, 1985; Nedvěd et al., 1995; Hodková \& Hodek, 1997). Even though slight mortality of diapause eggs was observed after prolonged exposure at sub-zero temperature (Ltime ${ }_{50}$ at $-25^{\circ} \mathrm{C}$ was about 44 days), this may not have been caused by low temperature injury but by dehydration (Renault et al., 2002). Thus the supercooling capacity of grasshopper eggs might indeed be a convenient indicator of their cold hardiness.

Cold hardiness strategies of insects are often divided into two types with respect to their cold tolerance and overwintering strategies. Freeze-tolerant insects survive freezing; they can tolerate temperatures below their SCP. Freeze intolerant insects freeze and die at their SCPs. The freeze intolerance strategy is further divided into four more classes: freeze avoidance, chill tolerance, chill susceptibility, and opportunistic survival (Bale, 1993, 1996). The freeze avoidance strategy is similar to the freeze intolerance, but with a strict definition. Bale (1993) cited only two species, the moths Epiblema scudderiana and Epirrita autumnata, as examples of freeze avoidance that survive exposures "as long as the minimum winter temperatures remain above the SCP". Considering the close correlation of SCP and lower lethal temperature, as well as very slight increase of mortality with time at temperature just above SCP (lethal time at $-25^{\circ} \mathrm{C}$ ), diapause eggs of $C$. fallax can be classified as freeze avoiding species (Bale, 1996) or the cold injury class DOC (Nedvěd, 2000b). Chorthippus fallax may represent the first experimental example of true freeze avoiding insect, while the previous examples, the moths E. scudderiana and E. autumnata, were suggested as freeze avoiding only according to ambient air temperature measurements (Virtanen et al., 1998; Nedvěd, personal communication).

\section{Diapause and acclimation}

Diapause is a genetically programmed process that enables insects to tolerate predictably unfavorable conditions, such as extreme temperatures, drought or limited food supply. There is conflicting evidence as to the existence of a relationship between diapause and cold hardiness (Denlinger, 1991; Pullin, 1996; Košt'ál \& Šimek, 1995; Košt’ál et al., 2001). In some insects species, supercooling capacity or cold hardiness in the diapause stage is higher than that of the non-diapause stage, suggesting that cold hardiness is likely to be an integral part of diapause (Hodková \& Hodek, 1994; Han et al., 1995; Milonas \& Savopoulou, 1999; Watanabe \& Tanaka, 1999; Jo \& Kim, 2001; Šlachta et al., 2002). While in other species cold hardiness can occur completely independently of diapause (Salt, 1961; Ring, 1972). The eggs of C. fallax, however, differ from the above mentioned pattern since 
the SCPs of pre-diapause and diapause eggs are similar, but significantly lower than that of post-diapause eggs.

By comparing the distribution of SCPs and lethal temperature data, it is evident that the SCPs of the lower SCP group of eggs lie within the Ltemp $p_{10}$ and Ltemp $p_{90}$ values of sample groups. Analysis of local winter climate conditions (Fig. 4) suggests that pre-diapause and diapause eggs in the lower SCP group, but not post-diapause eggs in higher SCP group, could safely survive the lowest winter temperatures. Nonetheless, if spring or early summer temperatures are lower than $-8^{\circ} \mathrm{C}$, the postdiapause eggs would suffer severe cold injury and high mortality.

It was reported that acclimation to low temperature can raise the supercooling capacity and cold tolerance of organisms (Fields et al., 1998). Our results also indicate that acclimation to low temperature can slightly increase the supercooling capacity of both pre-diapause and diapause eggs. The slow decline of temperature in autumn may also have acclimation effects and enhance the cold hardiness of $C$. fallax eggs with respect to the coming winter.

ACKNOWLEDGEMENTS. This research was supported by grants from the Chinese Academy of Sciences (KSCX1-08-03 and KSCX2-SW-1-03 and KZ951-B1-106-2) and the State Key Laboratory of Integrated Management of Pest Insects and Rodents. Sincere thanks are extended to R. Moorhouse for commenting on and editing the first draft of this manuscript and to O. Nedvěd and I. Hodek for review and suggestions on the manuscript. I also thank the Chinese Academy of Sciences Inner Mongolian Grassland Ecosystem Research Station for logistic support in the field and laboratory facilities.

\section{REFERENCES}

BALE J.S. 1993: Classes of insect cold hardiness. Func. Ecol. 7: 751-753.

BALE J.S. 1996: Insect cold hardiness: a matter of life and death. Eur. J. Entomol. 93: 369-382.

BALE J.S. 2002: Insects and low temperatures: from molecular biology to distributions and abundance. Phil. Trans. R. Soc. Lond. (B) 357: 849-862.

Block W., Li H.C. \& Worland R. 1995: Parameters of cold resistance in eggs of three species of grasshoppers from Inner Mongolia. Cryo-Letters 16: 73-78.

Chen B. \& KANG L. 2002: Cold hardiness and supercooling capacity in the pea leafminer Liromyza huidobrensis. CryoLetters 23: 173-182.

DenLINGER D.L. 1991: Relationship between cold hardiness and diapause. In: Lee R.E. \& Denlinger D.L. (eds): Insects at Low Temperature. Chapman \& Hall, New York \& London, pp. 174-198.

Fields P.G., Fleurat-Lessard F., Lavenseau L., Febray G., Peypelut L. \& Bonnot G. 1998: The effect of cold acclimation and deacclimation on cold tolerance, trehalose and free amino acid levels in Sitophilus granarius and Cryptolestes ferrugineus (Coleoptera). J. Insect Physiol. 44: 955-965.

FisheR J.R. 1997: Embryonic diapause in Aulocara elliotti and Ageneotettix deorum (Orthoptera: Acrididae): low-temperature relationships. Environ. Entomol. 26: 906-911.

GeHRKEN U. 1989: Diapause termination in eggs of the stonefly Arcynopteryx compacta (Mclachland) in relation to dehydration and cold hardiness. J. Insect Physiol. 35: 377-385.
HAN E.N. \& BAUCE E. 1995: Glycerol synthesis by diapause larve in response to the timing of low temperature exposure and implications for overwintering survival of the spruce budworm, Choristoneura fumiferana. J. Insect Physiol. 41: 981-985.

Hanson S.M. \& Craig G.B. JR. 1994: Cold acclimation, diapause, and geographic origin affect cold hardiness in eggs of Aedes albopictus (Diptera: Culicidae). J. Med. Entomol. 31: 192-200.

Hodková M. \& Hodek I. 1994: Control of diapause and supercooling by the retrocerebral complex in Pyrrhocoris apterus. Entomol. Exp. Appl. 70: 237-245.

Hodková M. \& Hodek I. 1997: Temperature regulations of supercooling and gut nucleation in relation to diapause of Pyrrhocoris apterus (L.) (Heteroptera). Cryobiology 34: 70-79.

JING X.H. \& KANG L. 2003: Geographical variation in egg cold hardiness: a study on the adaptation strategies of the migratory locust Locusta migratoria L. Ecol. Entomol. 28: 151-158.

Jo H.M. \& Kıм Y. 2001: Relationship between cold hardiness and diapause in the summer fruit tortrix, Adoxophyes orana (Fischer Von Roselerstam). J. Asia-Pacific Entomol. 4: 1-9.

Kalushrov P. \& Nedvěd O. 2000: Cold hardiness of Pyrrhocoris apterus (Heteroptera: Pyrrhocoridae) from central and southern Europe. Eur. J. Entomol. 97: 149-153.

KANG L. \& ChEN Y.L. 1994a: Multidimensional analysis of resource utilization in assemblages of grassland grasshoppers (Orthoptera: Acrididae). Entomol. Sinica 1: 264-282.

KANG L. \& CHEN Y.L. 1994b: Tropical niche of grasshoppers within steppe ecosystem in Inner Mongolia. Acta Entomol. Sinica 37: 178-189 (in Chinese, English abstr.).

KošŤÁL V. \& ŠimeK P. 1995: Dynamics of cold hardiness, supercooling and cryoprotectants in diapausing non-diapausing pupae of the cabbage root fly, Delia radicum L. J. Insect Physiol. 41: 627-634.

KošŤÁL V., ŠLACHTA M. \& ŠIMEK P. 2001: Cryoprotective role of polyols independent of the increase in supercooling capacity in diapausing adults of Pyrrhocoris apterus (Heteroptera: Insecta). Comp. Biochem. Physiol. (B) 130: 365-374.

LEE R.E. JR. 1991: Principles of insect low temperature tolerance. In Lee R.E. \& Denlinger D.L. (eds): Insects at Low Temperature. Chapman \& Hall, New York \& London, pp. $17-46$.

Lee R.E. JR. \& Denlinger D.L. 1985: Cold tolerance in diapausing and non-diapausing stage of the flesh fly, Sarcophaga crassipalpis. Physiol. Entomol. 10: 309-315

Li H.C. \& Chen Y.L. 1985: Studies on the feeding behavior of Acridoids in typical steppe subzone of Nei Mongol (Inner Mongolia) Autonomous Region II. Characteristics of food selection in natural plant communities. Res. Grassl. Ecosyst. 1: 154-156 (in Chinese, English abstr.).

Li H.C. \& KANG L. 1991: The eco-geographical conditions for grassland insects in Inner Mongolia. In Ma Y., Li H.C. \& Kang L. (eds): The Grassland Insects of Inner Mongolia. Tianze Eldonejo, Beijing, pp. 1-99 (in Chinese, English abstr.).

Li H.C., XI R.H. \& Chen Y.L. 1983: Study on the feeding behavior of acridoids in typical steppe subzone of Nei Mongol (Inner Mongolia) Autonomous Region I: Characteristics of food selection within the artificial cages. Acta Ecol. Sinica 3: 241-228 (in Chinese, English abstr.).

Li H.C., WANG Z. \& Chen Y.L. 1987: Food consumption and utilization by three species of Acridoids (adult stage) in typical steppe. Acta. Ecol. Sinica 7: 331-338 (in Chinese, English abstr.). 
LiU J.P., Xi R.H., Li W.B. \& WANG Z.Z. 1990: Illustrated Handbook of Chinese Acridoid Eggs. Tianze Eldonejo, Beijing (in Chinese, English abstr.).

Lockwood J.A., Li H.C., Dodd J.L \&. Williams S.E. 1994: Comparison of grasshopper (Orthoptera: Acrididae) ecology on the grasslands of the Asian steppe in Inner Mongolia and the Great plains of North America. J. Orthop. Res. 2: 4-14.

LozINA-LozInski L.K. 1974: Studies in Cryobiology. John Wiley, New York, pp. 69-84.

Milonas P.G. \& Savopoulou-Soultani M. 1999: Cold hardiness in diapause and non-diapause larvae of the summer fruit tortrix, Adoxophyes orana (Lepidoptera: Tortricidae). Eur. J. Entomol. 96: 183-187.

Nedvěd O., Hodková M., Brunnhofer V. \& Hodek I. 1995: Simultaneous measurement of low temperature survival and supercooling in sample of insects. Cryo-Letters 16: 108-113.

NEDVĚD O. 2000a: Chill tolerance in the tropical beetle Stenotarsus rotundus. Cryo-Letters 21: 25-30.

NEDVĚD O. 2000b: Snow white and the seven dwarfs: a multivariate approach to classification of cold tolerance. CryoLetters 21: 339-348.

Pullin A.S. 1996: Physiological relationships between insect diapause and cold tolerance: Coevolution or coincidence? Eur. J. Entomol. 93: 121-129.

RAMLøV H. 1999: Microclimate and variation in haemolymph composition in the freezing-tolerant New Zealand alpine weta, Hemideina maori Hutton (Orthoptera: Stenopelmatidae). J. Comp. Physiol. (B) 169: 224-235.

RAMløv H., BedFord J. \& LeAder J. 1992: Freezing tolerance of the New Zealand alpine weta. J. Therm. Biol. 17: 51-54.

Renault D., Salin C., Vannier G \& Vernon P. 2002: Survival at low temperature in insects: what is the ecological significance of the supercooling point? Cryo-Letters 23: 217-228.

RiNG 1972: Relationship between diapause and supercooling in blowfly, Lucilia sericata (Mg.) (Diptera: Calliphoridae). Can. J. Zool. 50: 1601-1605.
Salt 1961: Principles of insect cold hardiness. Annu. Rev. Entomol. 6: 55-74.

Shintani Y. \& Ishikawa Y. 1999: Geographic variation in cold hardiness of eggs and neonata larvae of the yellow spotted longicorn beetle Psacothea hilaris. Physiol. Entomol. 24: 158-164.

Šlachta M., VAmbera J., ZahradníčKova H. \& KošŤÁL V. 2002: Entering diapause is a prerequisite for successful coldacclimation in adult Graphosoma lineatum (Heteroptera: Pentatomidae). J. Insect Physiol. 48: 1031-1039.

Søмme L. 1982: Supercooling and winter survival in terrestrial arthropods. Comp. Physiol. (A) 73: 519-543.

Søмme L. 1996: The effect of prolonged exposures at low temperatures in insects. Cryo-Letters 17: 341-346.

Søмme L. 2000: The history of cold hardiness research in terrestrial arthropods. Cryo-Letters 21: 289-296.

Storey K.B. \& Storey J.M. 1988: Freeze tolerance in animals. Physiol. Rev. 68: 27-84.

Strathdee A.T., Howling G.G. \& Bale J.S. 1995: Cold hardiness of overwintering aphid eggs. J. Insect Physiol. 41: 653-657.

VAN HoRn S.N. 1966: Studies on the embryogenesis of Aulocara elliotti (Thomas) (Orthoptera: Acrididae). J. Morphol. 120: 83-114.

Virtanen T., Neuvonen S. \& Nikula A. 1998: Modelling topoclimatic patterns of egg mortality of Epirrita autumnata (Lepidoptera: Geometridae) with a geographical information system: Predictions for current climate and warmer climate scenarios. J. Appl. Ecol. 35: 311-322.

Watanabe M. \& TANAKA K. 1999: Cold tolerance strategy of the freeze intolerance chrysomelid, Aulacophora nigripennis (Coleoptera: Chrysomelidae), in warm temperature regions. Eur. J. Entomol. 96: 175-181.

Zhao Y.X. \& Kang L. 2000: Cold tolerance of the leafminer Liromyza sativae (Diptera: Agromyzidae). J. Appl. Entomol. 124: $185-189$.

Received April 2, 2003; revised July 16, 2003; accepted September 12, 2003 